\title{
A Compact W shape Snow Fractal Multiband Antenna for Wireless Applications
}

\author{
Zhen $\mathrm{Yu}^{1,2, a}$, Jianguo $\mathrm{Yu}^{2, \mathrm{~b}}$ and Xiaoying Ran ${ }^{1, \mathrm{c}}$ \\ ${ }^{1}$ North China Institute of Science and Technology (NCIST), China \\ ${ }^{2}$ Beijing University of Posts and Telecommunications (BUPT), China \\ aYzyuzhen@ncist.edu.cn, byujg@bupt.edu.cn, c starsky202@ncist.edu.cn
}

\begin{abstract}
Keywords: W shape fractal; multi-broadband antenna; compact antenna; CPW-fed
Abstract. A novel compact W shape snow fractal multi-broadband planar antenna is proposed for mobile handsets in the paper. W shape two iteration fractal structure is combined with hexagonal monopole radiator, a nested concentric hexagon slot and coplanar waveguide (CPW) feed structure. The antenna can cover more than ten mobile applications in two broad-bands with -6dB bandwidth of $130.4 \% \quad(0.51-2.42 \mathrm{GHz})$ for UHF(606-806MHz), GSM900(880-960MHz), DCS1800(1710-1880MHz), TD-SCDMA(1880-2025MHz), WCDMA(1920-2170MHz), CDMA2000(825-880), LTE33-40(1900-2400MHz), LTE44(703-803MHz), WiFi, Bluetooth, and $11.49 \%(3.2-3.59 \mathrm{GHz})$ for WiMAX wireless applications. The proposed antenna is fabricated on a $1.6 \mathrm{~mm}$-thick FR4 substrate with dielectric constant of 4.4, and the size is $98 * 56 \mathrm{~mm}^{2}$. The good agreement between the measurement results and the simulation validates the proposed design approach and meets the requirements for various wireless applications.
\end{abstract}

\section{Introduction}

With the rapid development of mobile communication systems, miniaturized multiband planar antennas have been widely used in wireless mobile handsets because of its light weight, low profile, low cost, high manufacturing precision, easy to load, easy integration, etc. Resonance antennas, such as half-wave dipoles or quarter-wave monopoles are difficult to achieve multiband and miniaturization[1-2].Therefore, asymmetric CPW-fed antenna are used to improve the bandwidth[3]. Meanwhile, CPW-fed is the most popular feeding structures adopted in recent literatures[4-6].

In order to better achieve the multiband and miniaturization, many technologies have been studied, such as coupling feed technology [7-9], slot loaded technology [10-11], loading matching network [12], loading printed distributed inductance technology [13] and fractal technology [14]. Especially, fractal design approach on controlling the current path and resonant mode on radiators with the fractal space-filling to increase the antenna electrical length and radiation efficiency is usually adopted. Fractal structure design approaches are known for their compact size, low profile and multiband response. In [15], proposed a monopole antenna with new hybrid dielectric resonator antenna (DRA) excited by new fractal structure, which provide a huge bandwidth ranging from 2 to 40GHz. In [16], proposed an antenna with square and Giuseppe Peano fractal geometries on two layers microstrip antenna which covered GPS, Hiper-Lan2, IEEE 802.11b/g applications. In [17], a multiband Minkowski fractal coplanar waveguide (CPW)-fed slot antenna loaded with a dielectric resonator for multiple wireless standards.

In this paper, a novel compact two iterations W-shape snow fractal microstrip antenna with a nested concentric hexagon slot structure for multi-broadband wireless applications is presented. The antenna covers more than ten mobile applications of UHF(606-806MHz), GSM900(880-960MHz), DCS1800(1710-1880MHz),TD-SCDMA(1880-2025MHz),WCDMA(1920-2170MHz),CDMA2000 (825-880), LTE33-40(1900-2400MHz), LTE44(703-803MHz), WiFi, Bluetooth and WiMAX. 


\section{Antenna structure and design procedure}

\section{a. Characteristics of Antenna Structure}

The antenna is based on hexagonal snowflakes structure monopole radiator, and two isosceles triangles are digged on each edge of the hexagon to form a W shape. The same method is used to dig two smaller isosceles triangles on each remaining side to form $\mathrm{W}$ shape two iterations fractal structure. This will prolong the length of suface current on radiator, and will produce different frequency resonance points.

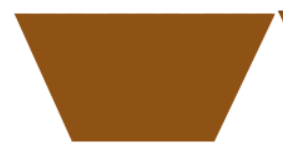

(a) no iteration

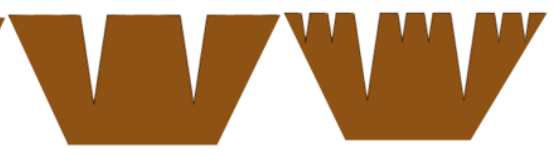

(b) 1st iteration (c) 2nd iteration

Fig.1 stepwise iteration stages on each side of the radiator

The structure and dimensions of proposed multiband monopole antenna is shown in Fig.2 and Table 1. The antenna has two iterations $\mathrm{W}$-shape fractal structure radiator with a concentric hexagon slot nested, a $50-\Omega \mathrm{CPW}$ feedline. The antenna is designed on FR4 substrate with height of $1.6 \mathrm{~mm}$, dielectric constant $\left(\varepsilon_{\mathrm{r}}\right)$ of 4.4 and loss tangent $(\delta)$ of 0.02 .
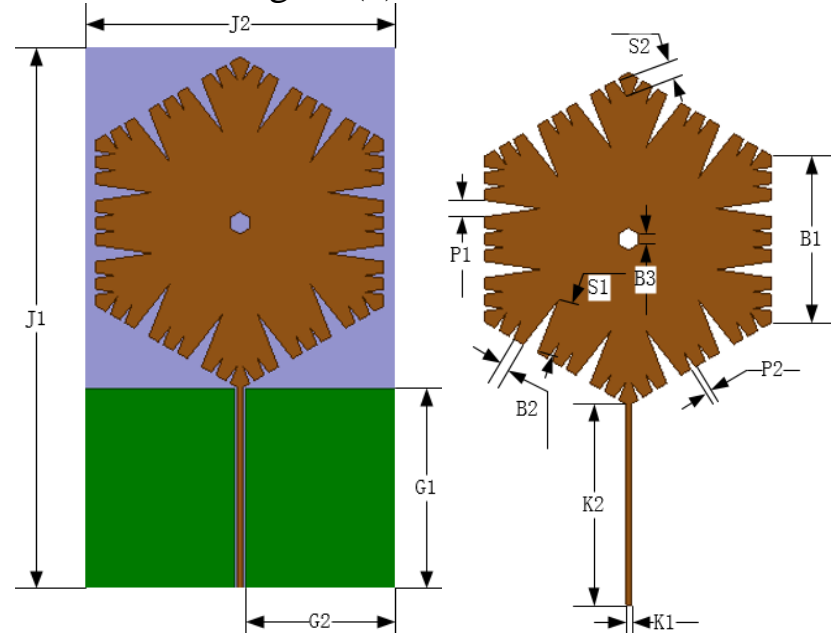

Fig.2. Layout of proposed antenna

Table 1. Dimensions of proposed antenna

\begin{tabular}{llllllll}
\hline \multicolumn{7}{l}{ Fractal Antenna Dimensions/Values(mm) } \\
\hline J1 & J2 & G1 & G2 & K1 & K2 & B1 & B2 \\
\hline 98 & 56 & 36 & 27 & 1 & 36.3 & 30 & 2 \\
\hline B3 & P1 & P2 & S1 & S2 & & & \\
\hline 2 & 3 & 1 & 10.1 & 3.4 & & & \\
\hline
\end{tabular}

\section{b. Performance of Simulation}

The simulation is conducted by Ansoft HFSS 15.0. Fig.3 illustrates the reflection loss $\left(\mathrm{S}_{11}\right)$ curves at different ground length. 


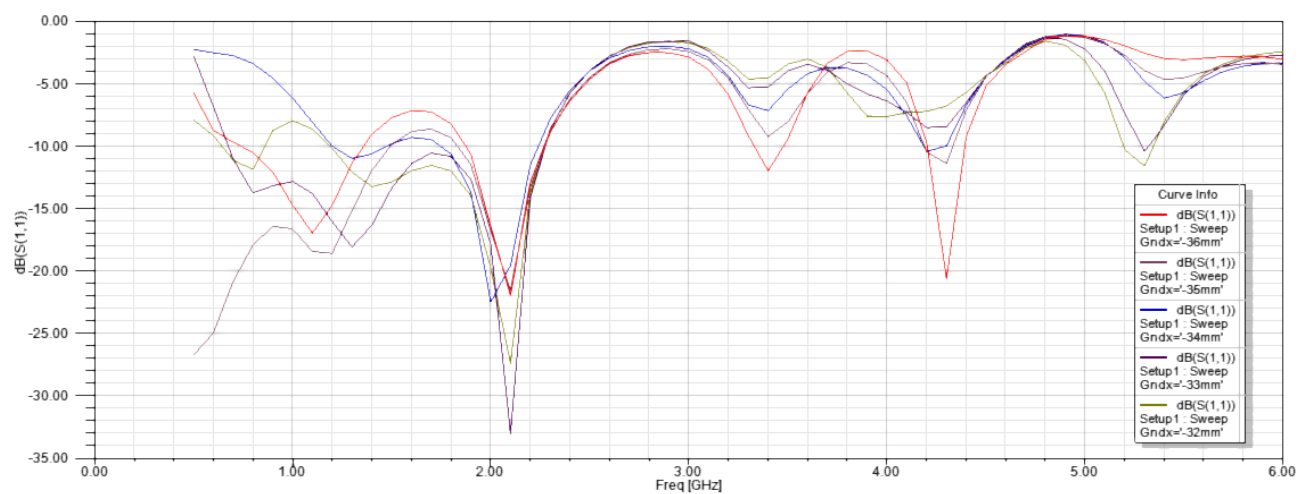

Fig.3. Combined simulated reflection loss of antenna

Fig.4 shows that the antenna can operate at four different wide frequency bands centered at $1.1 \mathrm{GHz}$ with $-16.95 \mathrm{~dB}$ reflection loss, $2.1 \mathrm{GHz}$ with $-21.7 \mathrm{~dB}$ reflection loss, $3.4 \mathrm{GHz}$ with $-11.9 \mathrm{~dB}$ reflection loss, and $4.3 \mathrm{GHz}$ with $-20.5 \mathrm{~dB}$ reflection loss. The simulated $-10 \mathrm{~dB}$ bandwidth for the first frequency band $(0.74-1.37 \mathrm{GHz})$ is $59.72 \%$, the second band $(1.87-2.27 \mathrm{GHz})$ is $19.32 \%$, the third band $(3.33-3.48 \mathrm{GHz})$ is $4.4 \%$ and the fourth band $(4.20-4.39 \mathrm{GHz})$ is $4.4 \%$. The $-6 \mathrm{~dB}$ bandwidth for the first frequency band $(0.51-2.42 \mathrm{GHz})$ is $130.4 \%$, the second band $(3.2-3.59 \mathrm{GHz})$ is $11.49 \%$, and the third band $(4.12-4.48 \mathrm{GHz})$ is $8.4 \%$. Fig.5 shows the voltage standing wave ratio (VSWR) curve of the antenna.These bands cover several commercial application bands of 2G, 3G, 4G-LTE, WiFi, Bluetooth and WiMAX, as given in Table 2 and Table 3.

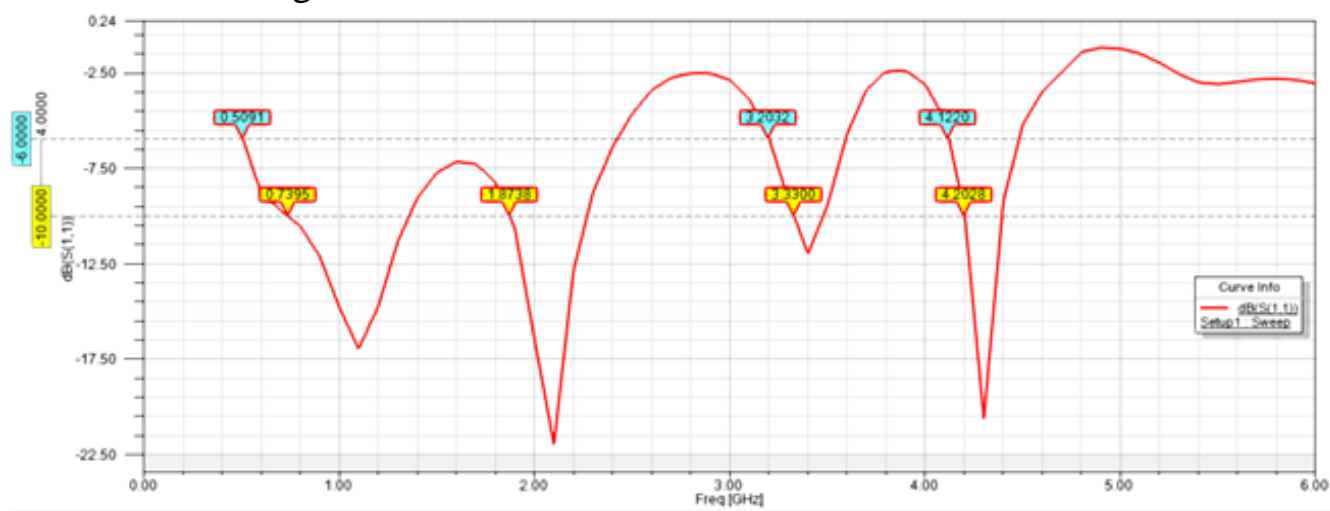

Fig.4. Simulated return loss $\left(\mathrm{S}_{11}\right)$ of proposed antenna

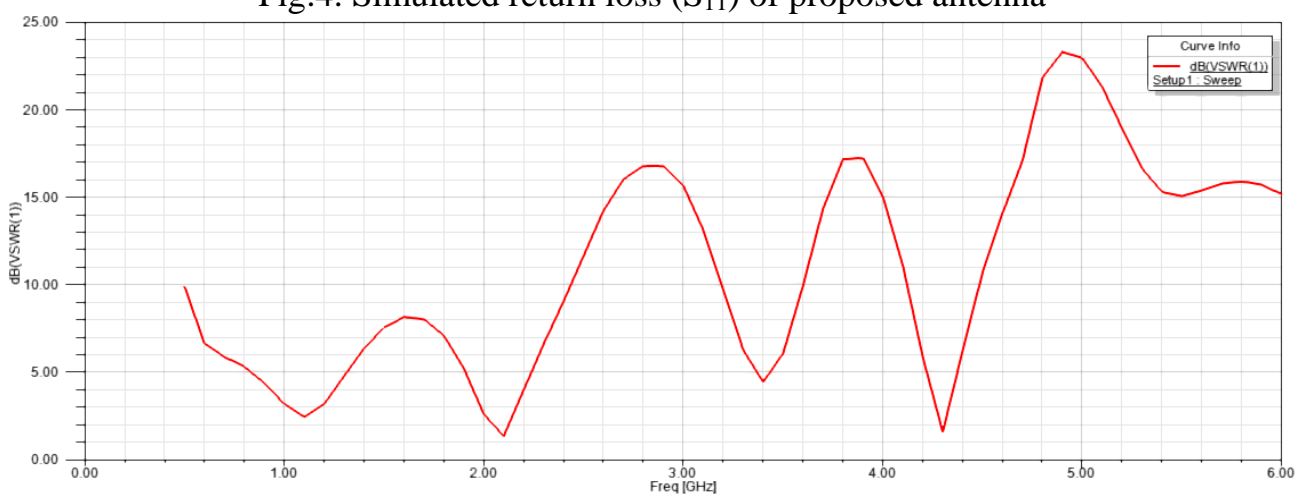

Fig.5. Simulated VSWR of proposed antenna

Table 2. - 10dB frequency bands covered by antenna

\begin{tabular}{|c|c|c|}
\hline Band No. & $\begin{array}{c}\text {-10dB } \\
\text { Bandwidth }\end{array}$ & Covered Commercial Bands \\
\hline 1 & $\begin{array}{c}0.74-1.37 \mathrm{GHz} \\
(59.72 \%)\end{array}$ & GSM900(880-960MHz), CDMA2000(825-880,885-960MHz) \\
\hline 2 & $\begin{array}{c}1.87-2.27 \mathrm{GHz} \\
(19.32 \%)\end{array}$ & TD-SCDMA(1880-2025MHz),WCDMA(1920-2170MHz), \\
LTE33-37(1900-2025MHz)
\end{tabular}


Table 3. - $6 \mathrm{~dB}$ frequency bands covered by antenna

\begin{tabular}{|c|c|l|}
\hline Band No. & $\begin{array}{c}\text {-6dB } \\
\text { Bandwidth }\end{array}$ & \multicolumn{1}{c|}{ Covered Commercial Bands } \\
\hline & & $\begin{array}{l}\text { UHF(606-806MHz),GSM900(880-960MHz), } \\
\text { DCS1800(1710-1880MHz),TD-SCDMA(1880-2025MHz,2300- } \\
2400 \mathrm{MHz} \\
\text { supplementary),WCDMA(1920-2170MHz, 1755-1880MHz } \\
\text { Supplementary),CDMA2000(825-880,885-960MHz } \\
\text { Supplementary), LTE33-40(1900-2400MHz), } \\
\text { LTE44(703-803MHz), WiFi, Bluetooth }\end{array}$ \\
& $\begin{array}{l}0.51-2.42 \mathrm{GHz} \\
(130.4 \%)\end{array}$ \\
\hline 2 & $\begin{array}{c}3.2-3.59 \mathrm{GHz} \\
(11.49 \%)\end{array}$ & WiMAX(3.3-3.48GHz) \\
\hline
\end{tabular}

The surface current amplitude distribution on radiator of the proposed antenna that work at the center frequency of $1.1 \mathrm{GHz}, 2.1 \mathrm{GHz}, 3.4 \mathrm{GHz}$, and $4.3 \mathrm{GHz}$, respectively, are shown in Fig.6(a)-(d). For $1.1 \mathrm{GHz}$ frequency, the current is more concentrated at the bottom of the radiator, as shown in Fig.6(a). With the frequency increase, the outer edges of the radiator has more current. While for $4.3 \mathrm{GHz}$ frequency, the current is relatively maximum at all edges of the radiator, as shown in Fig.6(d).

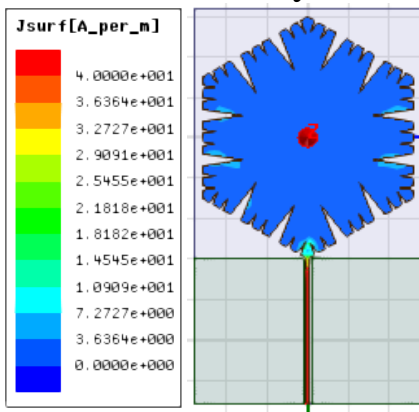

(a) $1.1 \mathrm{GHz}$

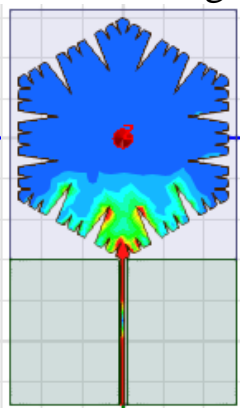

(b) $2.1 \mathrm{GHz}$

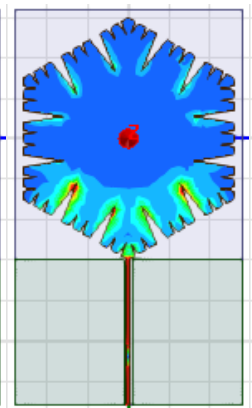

(c) $3.4 \mathrm{GHz}$

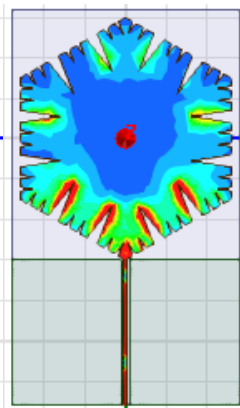

(d) $4.3 \mathrm{GHz}$

Fig.6 Current amplitude distribution at different center frequencies

The simulated E-plane and $\mathrm{H}$-plane radiation patterns of proposed antenna at the center frequencies of $1.1 \mathrm{GHz}, 2.1 \mathrm{GHz}, 3.4 \mathrm{GHz}$ and $4.3 \mathrm{GHz}$ are shown in Fig.7(a)-(d). It can be seen that E-plane and $\mathrm{H}$-plane patterns are close to omnidirectional at all bands.
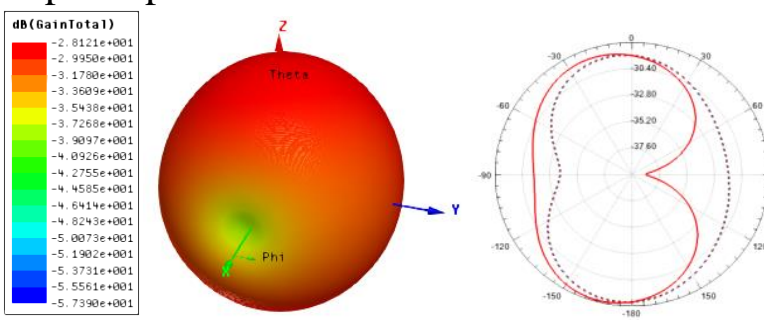

(a) $1.1 \mathrm{GHz}$

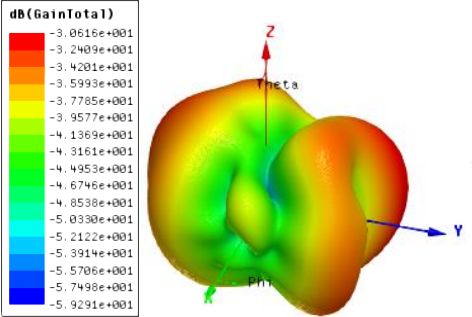

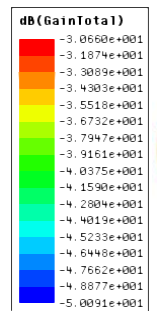
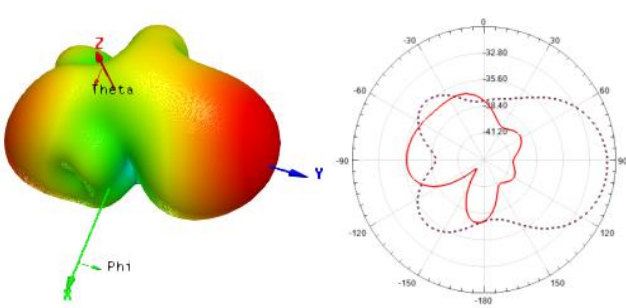

(b) $2.1 \mathrm{GHz}$

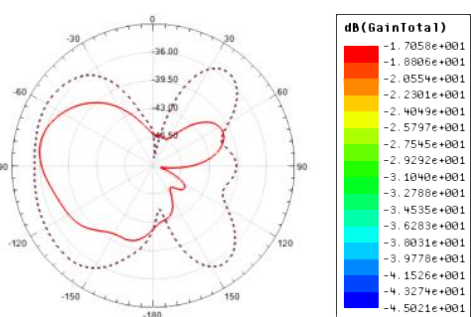

(c) $3.4 \mathrm{GHz}$

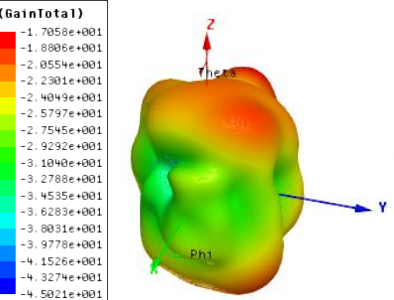

(d) $4.3 \mathrm{GHz}$

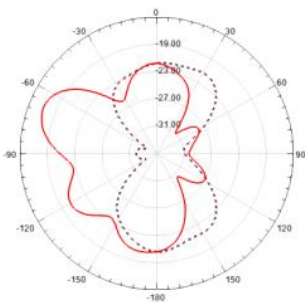

Fig.7. E- and H- plane radiation patterns at different center frequencies 


\section{Fabrication and measured results}

To verify the muilt-broadband performance of the planar antenna, a prototype antenna is fabricated and measured. The antenna is built on $1.6 \mathrm{~mm}$ thick FR4 substrate with loss tangent $=0.02$ and $30 \mu \mathrm{m}$ copper on both sides. Fig.8(a) shows the front and back views of the antenna. The antenna is tested by antenna measurement system of PNA3621, as shown in Fig.8(b).

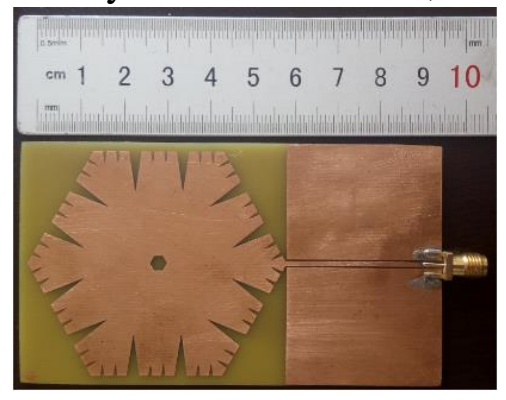

(a)

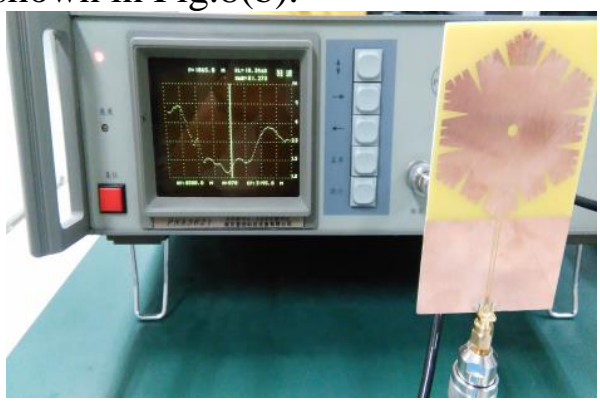

(b)

Fig.8 (a) Fabricated prototype antenna and (b)Testing scenario

The measured reflection loss $\left(\mathrm{S}_{11}\right)$ and Voltage Standing Wave Ratio (VSWR) have better agreement with the simulated results, as shown in Fig.9. This makes the antenna compatible for mobile communications applications.

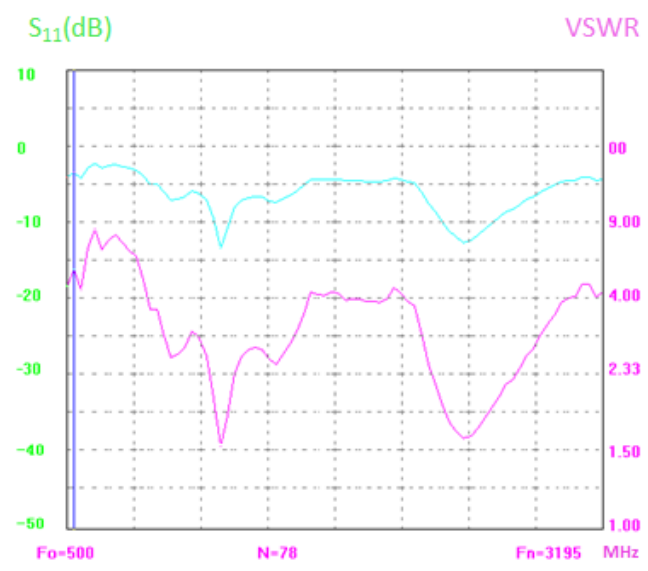

Fig.9. Measured $\mathrm{S}_{11}$ and VSWR curves

\section{Conclusions}

A W-shape structure snow fractal multiband planar antenna is developed for GSM900, DCS1800, TD-SCDMA, WCDMA, CDMA2000, LTE, Bluetooth and WiMAX applications. The better agreement between the measurement results and the simulation validates the proposed antenna meet the requirements for various wireless applications.

\section{Acknowledgements}

This work is financially supported by the National Natural Science Foundation of China (No.61372035), LangFang city Science and Technology Research and Development Program (No.2016011007) and Scientific Research Project of Central Universities of NCIST (No. $3142013050)$.

\section{References}

[1] X. L. Sun, L. Liu, S. W. Cheung, and T. I. Yuk: Dual-band Antenna with Compact Radiator for 2.4/5.2/5.8 GHz WLAN Applications, IEEE Trans. Antennas Propag., vol.60, no.12, pp.5924-5931, Dec. 2012. 
[2] M. J. Hua, P.Wang, Y. Zheng, and S. L. Yuan: Compact Tri-band CPW-fed Antenna for WLAN/WiMAX Applications, Electronics Letters, vol.49, no.18, pp.1118-1119, 2013.

[3] C. J. Wang and K. L. Hsiao: CPW-fed Monopole Antenna for Multiple SystemIntegration, IEEE Trans. Antennas Propag., vol. 62, no.2, pp.1007-1011, Feb. 2014.

[4] H. Chen, X. Yang, Y. Z. Yin, J. J. Wu, and Y. M. Cai: Tri-band Rectangle-loaded Monopole Antenna with Inverted-L slot for WLAN/WiMAX Applications, Electronics Letters, vol. 49, no.20, pp. 1261-1262, 2013.

[5] P. Liu, Y. Zou, B. Xie, X. Liu, and B. Sun: Compact CPW-fed Tri-band Printed Antenna with Meandering Split-ring Slot for WLAN/WiMAX Applications, IEEE Antennas and Wireless Propagation Letters, vol. 11, pp. 1242-1244, 2012.

[6] W. C. Liu, C. M. Wu, and N. C. Chu: A Compact CPW-Fed Slotted Patch Antenna for Dual-band Operation, IEEE Antennas and Wireless Propag. Lett., vol. 9, pp. 110 - 113, 2010.

[7] D.-G. Kang and Y. Sung: Coupled-fed Planar Printed Shorted Monopole Antenna for LTE/WWAN Mobile Handset Applications, IET Microwaves, Antennas and Propagation, vol. 6, no. 9, pp. 1007-1016, 2012.

[8] Z. L. Xie, W. B. Lin, and G. L. Yang: Coupled-fed Printed Antenna for LTE Mobile Handset Applications, Microwave and Optical Technology Letters, vol. 56, no. 8, pp. 1752-1756, 2014.

[9] J. H. Chen, Y. L. Ban, H. M. Yuan, and Y. J. Wu: Printed Coupled-fed PIFA for Seven-band GSM/UMTS/LTE WWAN Mobile Phone, Journal of Electromagnetic Waves and Applications, vol. 26, no. 2-3, pp. 390-401, 2012.

[10] Z. Chen, Y.L. Ban, J. H. Chen, J. L.W. Li, and Y. J. Wu: Bandwidth Enhancement of LTE/WWAN Printed Mobile Phone Antenna Using Slotted Ground Structure, Progress in Electromagnetics Research, vol. 129, pp. 469 - 483, 2012.

[11] M. T. Wu, and M. L. Chuang: Multibroadband Slotted Bow-tie Monopole Antenna, IEEE Antennas and Wireless Propag. Lett., vol. 14, pp. 887-890, 2015.

[12] Y. L. Ban, Y. F. Qiang, Z. Chen, K. Kang, and J. L.W. Li: Lowprofile Narrow-frame Antenna for seven-band WWAN/LTE Smartphone Applications, IEEE Antennas and Wireless Propag. Lett., vol. 13, pp. $463-466,2014$.

[13] C. H. Chang and K. L. Wong: Small-size Printed Monopole with a Printed Distributed Inductor for Pentaband WWAN Mobile Phone Application, Microwave and Optical Technology Letters, vol. 51, no. 12, pp. 2903-2908, 2009.

[14] C. L. Nóbrega, M. R. Silva, P. H. Fonseca, et al: Simple, Compact, and Multiband Trequency Selective Surfaces Using Dissimilar Sierpinski Fractal Elements, International Journal of Antennas and Propagation, pp. 1-5, Nov. 2015.

[15] A. Azari, A. Ismail, A. Sali, and F. Hashim: A new Super Wideband Fractal Monopole-dielectric Resonator Antenna, IEEE Trans. Antennas Propag., vol. 61, no.8, pp.1014-1016, Aug.2013.

[16] O. Homayoon and H. Shahram: Circularly Polarized Multiband Microstrip Antenna Using the Square and Giuseppe Peano Fractals," IEEE Trans. Antennas Propag., vol. 60, no. 7, pp.3466-3470, Jul. 2012.

[17] S. Dhar, K. Patra, R. Ghatak, B. Gupta, and D. R. Poddar: A dielectric Resonator-loaded Minkowski Fractal-shaped Slot Loop Heptaband Antenna, IEEE Trans. Antennas Propag., vol. 63, no. 4, pp.1521-1529, Apr. 2015. 